\title{
KONTROL LAMPU PADA GEDUNG BERTINGKAT BERBASIS PERSONAL COMPUTER (PC)
}

\author{
Muh. Abdul Aziz*
}

\begin{abstract}
Abstrak. Need of electricity energy on the building, industries and firms mount increase, if we can not solve this increasing, it can influence needs of national electricity energy. While the establishing of new electricity generator about $1,2 \%$ in a year. This condition has to be perceived seriously by building constructor to convince the using of electricity energy by doing energy economical program. The purpose of this research is making a lamp control system on the building which can "on" or "of" the lamp by the electric swi tch in each of room and by program on PC. By doing this system, the lamp lamp controlling can be done easily, effective and efficient so that, it can economic electricity energy. This tool consists of two designs; they are mechanic design and electronic design. Mechanic design consists of room miniature, lamp which is connected with relay and Photodiode sensor. While electronic design consists of LM311, shift Register input, shift register output, ULN 2003 and DB 25. Then the tool is connected with PC through parallel port communication. This system is controlled by the main program on PC wich uses Delphi 7.0. Testing of sensor is done by looking for the tense is out from sensor when there is light and no light. While test of the whole tools by giving income (push) on the button/ the button on the program then look at the lamp output, whether it is match with incaome or not. From the testing result of the whole systems can be concluded that lamp control by using Delphi 7.0 can do wll. It shows same output to input given. If lamp is on, push the button on the program appearance. It will be yellow color and if lamp is broken or did not paired on the program button, it will be red color.
\end{abstract}

Kata Kunci: Kontrol, Lampu, Personal Computer $(P C)$

\section{PENDAHULUAN}

Kebutuhan energi listrik nasional terus meningkat. Peningkatan ini disebabkan pemakaian energi listrik yang besar pada gedung, industri dan pabrik. Di sisi lain, pemakaian energi listrik masyarakat juga sangat boros. Hal ini disebabkan karena kurang memperhatikan besar kecilnya daya (Watt) peralatan listrik yang digunakan. Menurut Martin Djamin, Staf Ahli Menteri Negara Riset dan Teknologi Bidang Energi Alternatif dan Terbarukan, bahwa total kapasitas terpasang pembangkit listrik PLN pada 2003 sebesar 21,61 GigaWatt (GW). Pembangunan pembangkit listrik yang baru adalah sebesar $1,2 \%$ per tahun, sementara kebutuhan listrik meningkat di atas $7 \%$ per tahun Kondisi ini akan berimbas pada sektor gedung perkantoran yang kebanyakan menggunakan energi listrik dari PLN.

Permasalahan ini harus ditanggapi secara seksama oleh para pengelola gedung untuk menekan pemakaian energinya. Salah satu cara yang paling mudah adalah dengan memanfaatkan energi secara maksimal melalui program hemat energi. Penghematan energi adalah pemanfaatan energi secara efisien dan rasional tanpa mengurangi penggunaaan energi yang memang benar-benar diperlukan. Penghematan energi pada gedung dan industri bila dilaksanakan secara sistematis akan berpotensi mengurangi konsumsi energi yang besar. Namun pada prakteknya program penghematan energi tersebut masih menemui beberapa kendala. Salah satu masalah yang dihadapi dalam melakukan penghematan energi adalah sistem pengontrolan lampu pada gedung saat ini masih tergolong konvensional yaitu dengan menggunakan saklar atau relatif hanya menggunakan prinsip pengontrolan jarak dekat (manual), sehingga untuk menghidupkan dan mematikan lampu harus dengan mendatangi saklar terlebih dulu.

Gedung-gedung yang memiliki jumlah ruangan yang banyak, sering kali

(*) SMP Al-Akbar (Bilingual School) Brondang Lamongan 
lampunya tetap menyala padahal sudah di luar jam kerja, bahkan kadang-kadang sampai pagi. Hal ini disebabkan oleh kelalaian pengguna ruangan dan juga petugas yang harus mengecek lampu pada setiap ruangan. Kondisi seperti ini akan menyebabkan pemborosan energi listrik apabila terjadi berulang-ulang. Oleh karena itu perlu adanya sistem kontrol lampu pada gedung yang lebih praktis dan efisien.

\section{KAJIAN TEORI \\ PersonalComputer(PC)}

Komputer adalah alat yang dipakai untuk mengolah data menurut prosedur yang telah dirumuskan. Kata computer semula dipergunakan untuk menggambarkan orang yang perkerjaannya melakukan perhitungan aritmatika, dengan atau tanpa alat bantu, tetapi arti kata ini kemudian dipindahkan kepada mesin itu sendiri. PC merupakan sebuah unit perangkat elektronik yang terdiri dari tiga unsur yaitu hardware, software dan brainware (Juwitasari, 2005).

\section{Hardware}

Hardware adalah seluruh himpunan elektronik dan mekanik yang menyusun sebuah komputer. Berdasarkan fungsinya hardware terbagi atas:

a. Alat Masukan (input device)

Sebuah komputer dapat bekerja ketika dimasukkan data atau perintah. Untuk memasukkan data atau perintah tersebut diperlukan peralatan khusus yang dinamakan alat masukan atau alat input. Beberapa contoh alat input diantaranya adalah keyboard atau papan ketik, mouse dll.(http://blogspot.com).

b. Alat Pemroses (processing device)

Data atau perintah yang telah dimasukkan dengan alat input selanjutnya akan diproses oleh komputer. Bagian yang berfungsi memproses data atau perintah disebut CPU (Central Processing Unit) (www.ilkom.unsri.ac.id).

c. Alat Keluaran (output device)

Setelah melalui pemroses, komputer akan menampilkan output atau hasil dari data atau perintah yang diberikan. Bagian dari komputer yang bertugas menampilkan hasil/output disebut alat keluaran/output. Contoh alat keluaran adalah monitor, printer dan disk drive. (Juwitasari, 2005).

d. Alat Penyimpan Data

Alat penyimpan data ini berfungsi untuk menyimpan data atau perintah. Contoh dari alat ini adalah Memori, Floppy Disk dan Hard Disk.

\section{Software}

Software adalah sekumpulan perintah atau data yang diolah komputer untuk menghasilkan keluaran yang diinginkan dari masukan yang diberikan. Contoh software antara lain (http://blogspot.com):

a.Sistem Operasi $\quad$ : DOS, Windows,Linux dll

b.Bahasa Pemrograman : Assembly, Pascal, Delphi dll

c.Paket Program : : Ms.Word, Excel dll

\section{Brainware}

Brainware adalah manusia yang mengendalikan/menjalankan komputer, atau disebut juga piranti otak. Sumber daya manusia sebagai brainware memegang peranan penting dalam suatu sistem kendali dengan komputer. Menurut fungsi dan perannya, sumber daya manusia dapat diklasifikasikan dalam dua golongan yaitu: (Juwitasari, 2005). 
a.Programmer dan Sistem Engineer

Programer dan Sistem Engineer adalah pencipta dari sistem kendali berbasis komputer. Mereka bertugas untuk merancang suatu sistem kendali secara keseluruhan, termasuk di dalamnya pembuatan aplikasi komputer dan menentukan perangkat keras apa saja yang terlibat dalam sistem kendali tersebut.

b.User/Operator

User/Operator adalah sumber daya manusia yang berinteraksi langsung dengan sistem pengendalian, pada saat sistem tersebut beroperasi

\section{Sistem Kontrol dengan Komputer}

Komputer merupakan peralatan elektronik yang dapat diprogram, menerima data, memproses data, menyimpan data, mengambil data serta menghasilkan data keluaran. Dengan perintah-perintah yang diberikan sebelumnya, komputer dapat melaksanakan suatu tugas tertentu. Perintah-perintah tersebut disebut dengan perangkat lunak atau program (Abdullah, 2003).

Salah satu aplikasi komputer adalah dalam bidang sistem kontrol. Konsep dasar sistem kontrol dengan komputer sangat sederhana.

\section{Interfacing (antarmuka)}

Interfacing (antarmuka) merupakan suatu cara menghubungkan komputer dengan piranti lain di luar komputer. Komputer dimanfaatkan sebagai pusat kendali untuk mengendalikan piranti di luarnya. Misal, mengendalikan motor, led/lampu, dan komputer juga dapat dimanfaatkan sebagai masukan dari sensor-sensor, saklar dan piranti input yang lain (Widodo, 2007).

Menurut Widodo (2007) bahwa untuk dapat berkomunikasi dengan d u n i a luar dalam teknik interfacing, komputer dapat memanfaatkan:

1.Saluran paralel melalui parallelport atau sering disebut sebagai port printer (LPT1).

2.Melalui serial port yaitu yang sering disebut sebagai COM port.

3.Melalui slot ekspansi, yaitu fasilitas dari sebuah komputer pribadi (PC) untuk keperluan antarmuka. Slot ini terdiri dari saluran alamat, data, kendali dan saluran catu daya

\section{ParallelPort}

Nama lain dari parallel port adalah printer port karena memang dirangcang untuk melayani pencetak paralel. Port parallel merupakan salah satu port komunikasi pada komputer PC. Port paralel ini terdiri dari 4 jalur kontrol, 5 jalur status dan 8 jalur data. Port ini terdapat pada bagian belakang PC dalam bentuk konektor DB-25 female (Iswanto, 2008). Port paralel distandarisasi oleh standart IEEE 1284 pada tahun 1994. Standart ini membedakan 5 mode operasi sebagai berikut (www.senet.com.au/ peacock):

1.Compatibility Mode

2.Nibble Mode (Protocol not Described in this Document)

3.Byte Mode (Protocol not Described in this Document)

4.EPP Mode (Enhanced Parallel Port)

5.ECP Mode (Extended Capabilities Port)

Compatibility mode hanya dapat mengirim data dari komputer pada kecepatan yang biasanya berkisar antara 80 kbyte perdetik. Agar komputer dapat menerima suatu data, nibblemode atau bytemode harus diterapkan. Nibblemode dapat menerima data sepanjang 1 byte ( 8 bit) (Iswanto, 2008). Ada dua macam konektor parallel port, yaitu 36 pin dan 25 pin. Konektor 36 pin dikenal dengan nama Centronics dan konektor 25 pin 
dikenal dengan DB25. Centronics lebih dahulu ada dan digunakan dari pada konektor DB-25. DB-25 diperkenalkan oleh IBM (bersamaan dengan DB-9, untuk serial port), yang bertujuan untuk menghemat tempat. Kar koneksitor parallel port pada komputer sekarang hanya digunakan DB-25. (www.teknisoft.netprojectskpl.php). Menurut Widodo (2007) port paralel mempunyai pin sebanyak 25 pin dengan tipe konektor female. Diagram skematik dari port tersebut adalah seperti gambar 1 berikut:

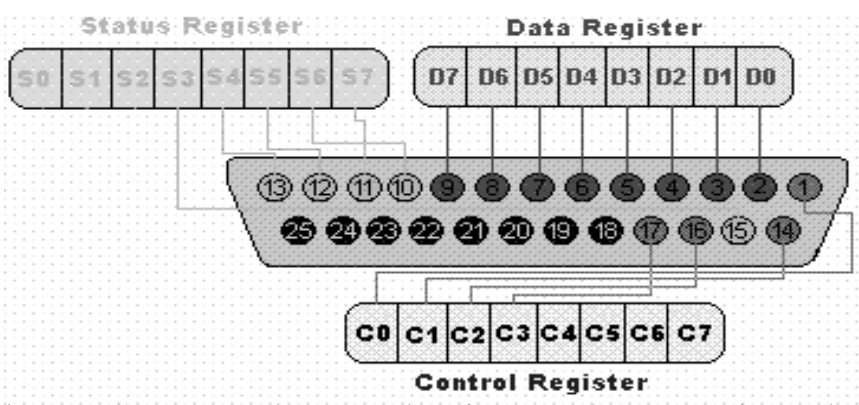

Gambar 1. Susunan dan pembagian DB25 Female pada LPT Port

(Sumber:Widodo, 2007)

Keterangan gambar:

1.Secara umum LPT port terbagi menjadi tiga saluran:

-Saluran Data : $\mathrm{D}_{0}$ sampai dengan $\mathrm{D}_{7}$; pin 2 sampai 9 bersifat output

-Saluran Status : $S_{3}$ sampai $S_{7}$; pin 15, 13, 12, 10 dan 11 bersifat sebagai input

-Saluran Control/Kendali : $\mathrm{C}_{0}$ sampai $\mathrm{S}_{3}$; pin 1, 14, 16 dan 17

2.Tanda $\mathrm{x}$ (garis di atas huruf dan abjad) menandakan aktif low.

3.Pin nomor 18 sampai dengan 25 terhubung ke ground (body).

4.Untuk saluran status $\mathrm{S}_{0}$ san $\mathrm{S}_{1}$ masih tercadang (belum digunakan), $\mathrm{S}_{2}$ tidak dikeluarkan ke pin DB25.

5.Saluran kendali $\mathrm{C}_{4}$ dan $\mathrm{C}_{5}$ tidak dikeluarkan ke pin, $\mathrm{C}_{6}$ dan $\mathrm{C}_{7}$ masih tercadang.

\section{Alamat ParallelPort}

Untuk dapat menggunakan port paralel, harus mengetahui alamatnya. Alamat LPT1 biasanya adalah 888 (378h) dan LPT2 biasanya 632 (278h). Alamat data port adalah alamat dari port paralel tersebut, alamat status port adalah kenaikan 1 angka dari data port, dan alamat controlport adalah kenaikan 2 angka dari data port. (Iswanto, 2008).

\section{Register ParallelPort}

Untuk register data, status dan kontrol pada parallelport masing-masing mempunyai alamat yang mengacu pada alamat dasar (base address) dari parallelport. Alamat dasar, biasanya dinamakan port data atau register data. Port Data digunakan untuk mengeluarkan data port paralel pada pin 2 sampai dengan 9. Register ini normalnya hanya bersifat "menulis" ( write only). Jika pada port ini diberikan instruksi membaca (read), maka yang terbaca adalah data yang terakhir terkirim. Tapi pada beberapa komputer yang telah dilengkapi standart IEEE 1284, port ini bersifat dua arah (bi-directional), sehingga ia juga dapat menerima (membaca) data (Iswanto, 2008).

Port status digunakan sebagai port baja. Data apa yang dituliskan pada port ini akan diabaikan. Port status berasal dari lima masukan port paralel (pin 10, 11, 12, 13 dan 15). Statusport adalah port yang hanya bersifat "membaca" ( read only). Setiap data yang dikirim melalui port ini akan diabaikan. Port status terdiri dari 5 jalur masukan yaitu pin $10,11,12,13$ dan 15. 
Port kontrol (alamat dasar +2 ) bertindak sebagai port "menulis" ( write only). Ketika sebuah printer dihubungkan ke port paralel, maka 4 kontrol akan digunakan, yaitu Strobe, AutoLinefeed, Initialize dan Select yang semuanya bersifat inverted kecuali initialize (Iswanto, 2008).

\section{Register Geser/Shift Register}

Register adalah suatu kumpulan flip-flop yang dapat secara bersama-sama menyimpan data biner dalam jumlah yang sangat banyak. Pada hakekatnya tak terbatas. Tetapi biasanya dikelompokkan berupa kelipatan 4 flip-flop dalam setiap register yang disebut dengan nibble. Register adalah kumpulan elemen-elemen memori yang bekerja bersama sebagai satu unit. Selain kemampuannya dalam menyimpan data, regsiter juga dapat menahan dan menggeser (shift) ke kiri dan ke kanan (Widjanarka, 2006).

Register geser disusun dengan merangkaikan flip-flop satu sama lain. Flip-flop mempunyai karakteristik memori. Karakteristik memori ini memberikan manfaat yang besar dalam register geser. Para ahli merangkai register geser dengan menggunakan gerbang individu dan flip-flop. Salah satu metode penentuan karakteristik register geser adalah bagaimana data dimuat ke dan dibaca dari unit-unit penyimpannya (Tokheim, 1990).

Register geser pada dasarnya merupakan koneksi seri dari Flip flop yang menggunakan clock untuk memindah data yang ada pada Flip flop sebelumnya dan dipindah ke data yang ada pada Flip flop selanjutnya (Putranto, 2008).

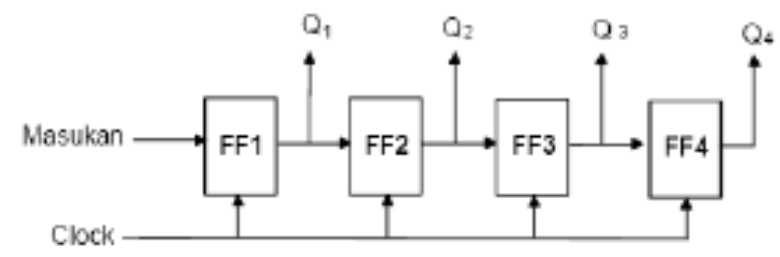

Gambar 2. Diagram blok register geser

(Sumber: Putranto, 2008)

Dalam sistem digital, register dibutuhkan untuk menyimpan atau memindahkan sekumpulan bit dalam format tertentu. Shift register memfasilitasi perpindahan data dalam format serial atau paralel dan menyimpan data tersebut. Gambar di bawah menampilkan model konversi sinyal serial ke paralel dan sebaliknya (Budiharto, 2005).

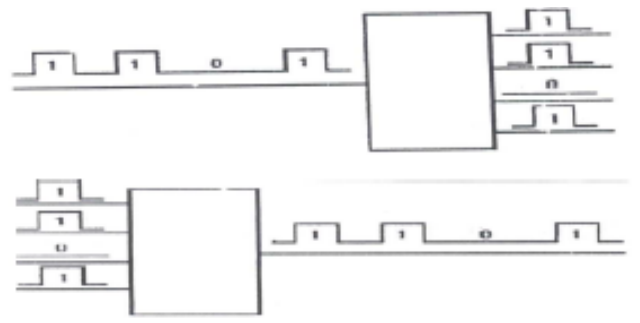

Gambar 3. Konversi sinyal serial ke parallel dan sebaliknya

(Sumber: Budiharto, 2005)

Untuk mengisi register atau untuk menyimpan data dapat dilakukan dengan dua cara (Soedarto, 2000):

1. Dimasukkan secara sejajar (Parallel In )

2. Dimasukkan secara seri (Serial In) 
Setiap penyimpan berbentuk register 8 bit. Register-regsiter tersebut adalah (Tokheim, 1996):

1. Masukan dan keluaran seri

2. Masukan seri, keluaran paralel

3. Masukan paralel, keluaran seri

4. Masukan dan keluaran parallel

\section{Fotodioda}

Fotodioda adalah dioda sambungan PN yang secara khusus dirancang untuk mendeteksi cahaya. Energi cahaya lewat melalui lensa yang mengekspos sambungan. Fotodioda dirancang beroperasi pada mode bias-mundur. Pada alat ini arus bocor bias-mundur meningkat dengan peningkatan level cahaya. Harga arus umumnya adalah dalam rentang microampere. Fotodioda mempunyai waktu respon yang cepat terhadap berbagai cahaya (Petruzella. 2001).

Bila energi cahaya menghujani persambungan $p-n$, ia juga dapat mengeluarkan elektron-elektron valensi. Dengan perkataan lain, jumlah cahaya yang menghujani persambungan dapat menghasilkan arus balik dioda. Fotodioda adalah salah satu alat yang dibuat untuk berfungsi paling baik berdasarkan kepekaannya terhadap cahaya. Pada dioda ini, sebuah jendela memungkinkan cahaya untuk masuk melalui pembungkus dan mengenai persambungan. Cahaya yang datang menghasilkan elektron bebas dan lubang. Makin kuat cahayanya, makin banyak jumlah pembawa minoritas dan makin besar arus baliknya (Malvino, 2003).

Gambar 4 menunjukkan lambang skematis fotodioda. Panah yang mengarah ke dalam melambangkan cahaya yang datang, yang teramat penting. Sumber dan tahanan seri memberi prategangan balik pada fotodioda. Bila cahaya makin cerah, arus balik naik. Dalam fotodioda yang lazim, arus balik tersebut besarnya sedekit puluhan mikroamper. Fotodioda adalah salah satu contoh fotodetektor yaitu sebuah alat optoelektronika yang dapat mengubah cahaya datang menjadi besaran listrik (Malvino, 1985).

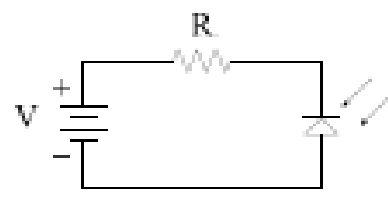

Gambar 4. Lambang skematik fotodioda

(Sumber, Malvino:1985)

\section{Relay}

Transistor tidak dapat berfungsi sebagai switch (saklar) tegangan AC atau tegangan tinggi yang arusnya lebih besar ( $>5$ amper). Sehingga dibutuhkan relay yang berfungsi sebagai saklar yang bekerja berdasarkan inputan yang dimilikinya (Budiharto, 2005).

Relay merupakan aplikasi elektromagnetik sesungguhnya, dimana ia tersusun atas kumparan kawat beserta sebuah inti besi lunak. Pada dasarnya relay adalah sakelar elektromagnetik yang bekerja apabila arus mengalir melalui kumparannya, sehingga inti besi menjadi magnet dan manarik kontak bila gaya magnet mengalahkan gaya pegas yang melawannya. Keuntungan relay sebagai berikut:

- Dapat switch AC dan DC.

- Relay dapat switch tegangan tinggi.

- Relay pilihan yang tepat untuk switch arus yang besar. 
- Relay dapat switch banyak kontak dalam 1 waktu

\section{Push Button/Tombol Tekan}

Tombol tekan merupakan salah satu jenis saklar yang tidak mempunyai pengunci secara mekanis. Adapun jenis tombol tekan adalah sebagai berikut (Suprayogi, 2006):

\section{Normally Open (NO)}

Tombol Tekan ini apabila ditekan akan menutup dan jika dilepaskan akan ke posisi semula (membuka).

2.Push Button Normally Closed (NC)

Tombol Tekan ini merupakan jenis tombol tekan yang dalam keadaan normalnya menutup. Jika tombol tersebut ditekan maka kaitannya akan membuka dan jika dilepaskan akan kembali pada keadaan semula yaitu menutup.

\section{Delphi}

Delphi merupakan pemrograman terstruktur yang berbasis pada obyek Pascal dari Borland, bekerja pada lingkup sistem operasi Windows. Struktur bahasanya dengan bahasa obyek pascal ini sangat mendukung untuk pemrograman OOP (Object-Oriented Pragramming ), maksudnya perluasan atas pemrograman terstruktur yang mengutamakan pemakaian ulang dan enkapsulasi data (kombinasi data dan funsionalitas ke dalam sebuah unit tunggal) berdasarkan fungsinya. Delphi juga mempunyai fungsi untuk memberikan fasilitas pembuatan aplikasi visual, sehingga meningkatkan produktivitas dalam pembuatan program yang meliputi kualitas pengembangan visual, kecepatan komplikasi, kekuatan bahasa pemrograman, fleksibilitas terhadap arsitektur basis data, dan pola desain (Iswanto, 2008).

\section{METODE PENELITIAN}

\section{Alat Dan Bahan}

Alat

1. Seperangkat komputer personal tipe pentium 4 CPU $2.66 \mathrm{GHz}$, harddisk 80 Gbyte, memori 240 Mbyte RAM dan sistem operasi Microsoft Windows $X P$ Professional untuk membuat program dan penulisan laporan.

2. Perangkat lunak (software) Delpi 7 untuk membuat program kontrol.

3. Multimeter

4. Solder Timah

5. Seperangkat komputer personal tipe pentium $4 \mathrm{CPU} 2.66 \mathrm{GHz}$, harddisk 80 Gbyte, memori 240 Mbyte RAM dan sistem operasi Microsoft Windows XPProfessional untuk membuat program dan penulisan laporan.

6. Perangkat lunak (software) Delpi 7 untuk membuat program kontrol.

7. Multimeter

8. Solder

9. Timah

\section{Bahan}

1. Shift Register input 76LS165 6 buah

2. Shift Register Output 76LS164 3 buah

3. Paralel port/LPT1 DB25

4. Fotodioda 24 buah

5. Driver sensor LM311 24 buah 
6. Relay SPDT, 8 pin, 12 volt 24 buah

7. ULN 2003

8. Saklar Push On 24 buah

9. Lampu 220 volt 24 buah

\section{Perancangan Alat}

Sistem yang dirancang bertujuan untuk mengontrol lampu pada gedung bertingkat, adapun perancangan alat yang digunakan dalam penelitian ini seperti dalam gambar 5 dibawah ini:

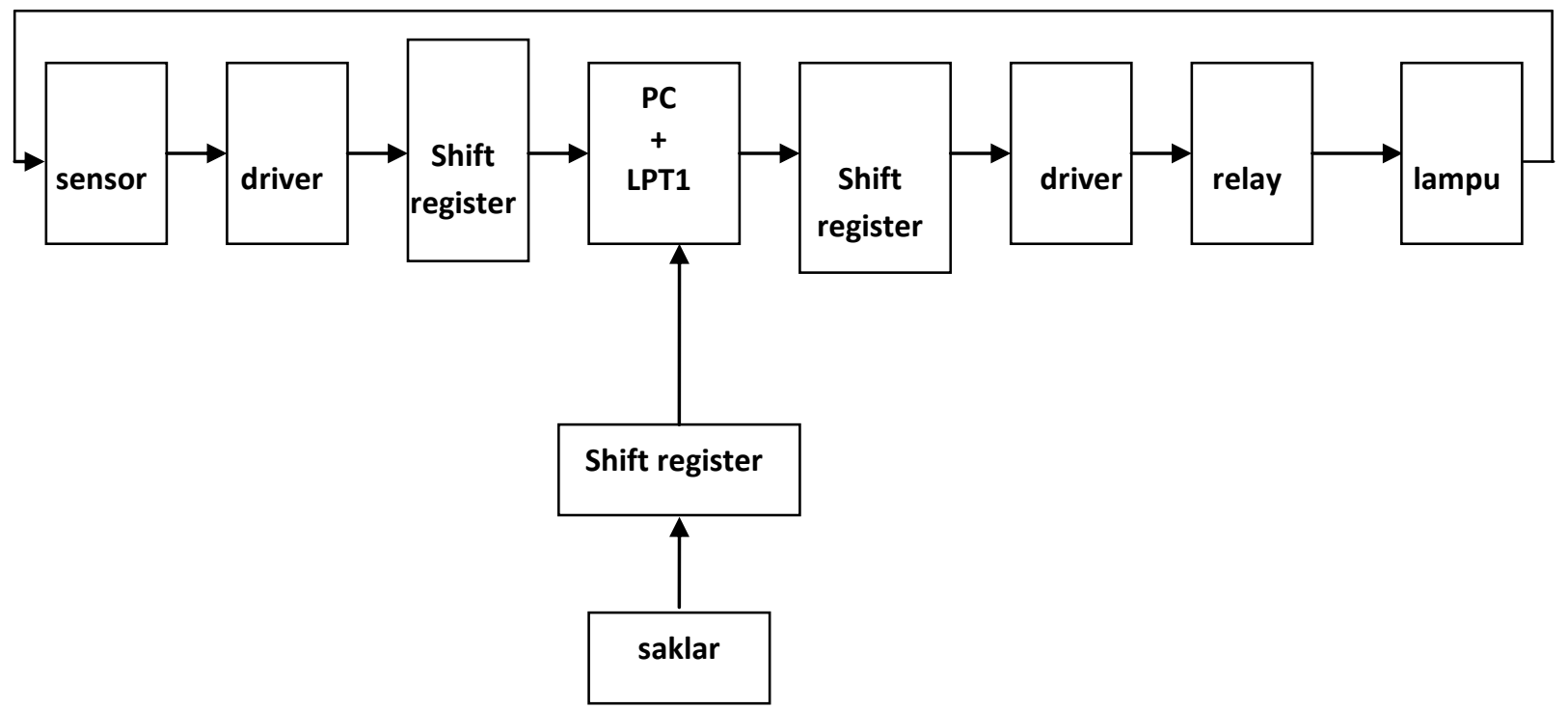

Gambar 5. Diagram Blok Sistem Keseluruhan

\section{Prinsip Kerja Diagram Blok Sistem}

Cara kerja alat ini adalah ketika saklar/tombol push botton ditekan atau dilepas akan memberikan masukan berupa logika 1 atau 0 , data ini akan disimpan dan dipindahkan oleh shift register input dengan cara serial ke port parallel pada PC. PC berfungsi sebagai pusat kontrol sistem akan mengolah data dan memberikan masukan ke shift register output. Sinyal masukan dari register output berupa logika 1 dan 0 akan dirubah menjadi tegangan dan dikuatkan oleh driver relay sehingga relay akan membuka dan menutup sesuai masukan yang diberikan. Sensor akan menangkap cahaya lampu dan merubah menjadi tegangan. Tegangan masukan $\mathrm{V}_{\text {in }}$ dari sensor akan dikuatkan dan diubah menjadi logika 0 dan 1 oleh rangkaian komparator. Data ini sebagai masukan pada PC yang akan menyalakan penanda lampu pada tampilan program.

Sistem perangkat keras yang dirancang menggunakan PC sebagai pengendali tidak akan dapat bekerja jika tidak disertai dengan perangkat lunak sebagai pengatur keseluruhan sistem. Perangkat lunak ini sebagai pengatur dan penghubung yang bertugas menentukan langkah-langkah yang harus dilakukan shift register baik input maupun output pada keseluruhan sistem, sehingga nantinya dapat ditentukan arah kendali atau proses dari sistem yang dibuat. Perangkat lunak yang dirancang pada sistem ini menggunakan Delphi. Adapun flow cart perangkat lunak sebagai berikut: 


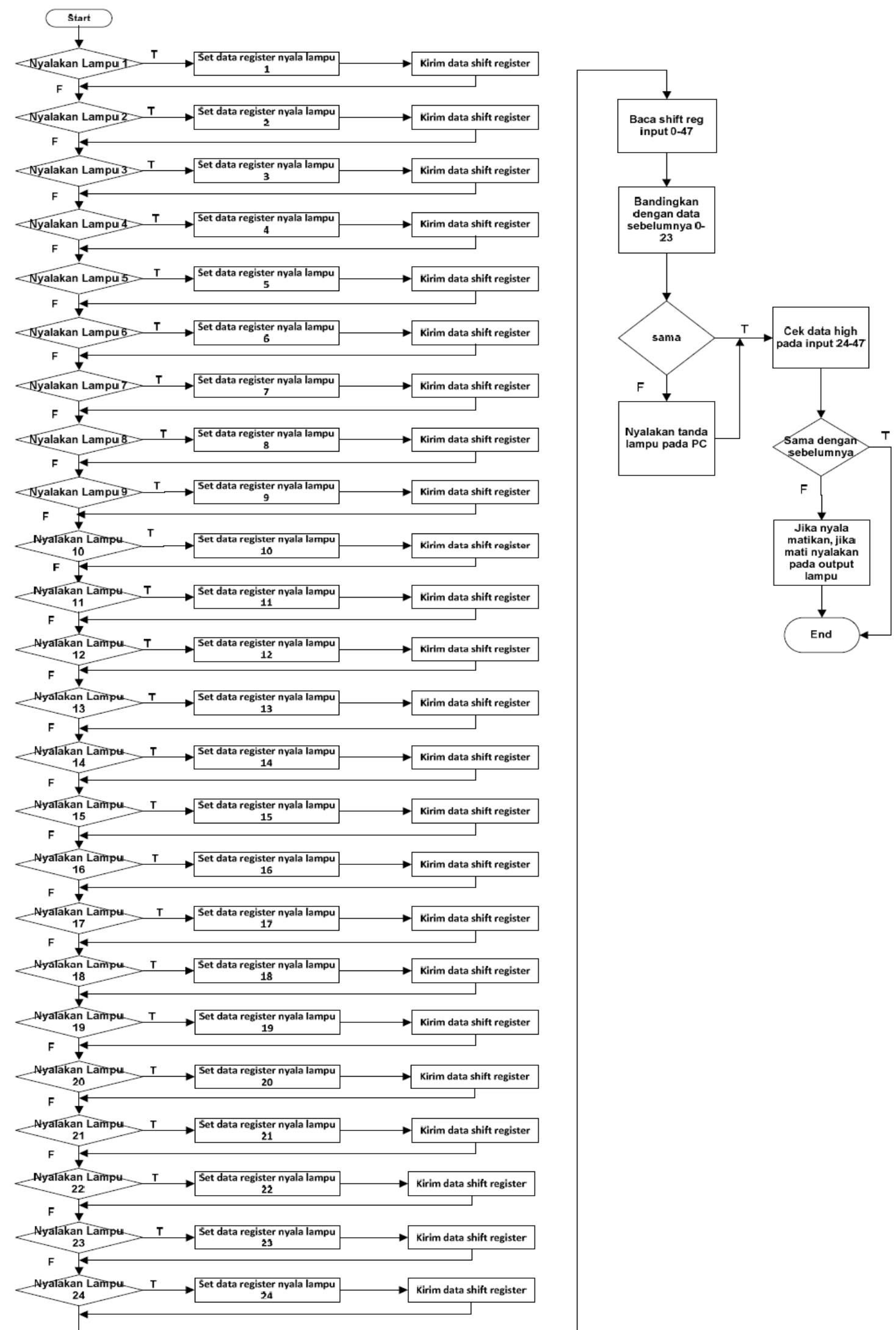

Gambar 6. Diagram alir perangkat lunak

\section{Uji Kontrol Lampu Pada Gedung Bertingkat Berbasis PC}

Pengendalian sistem secara keseluruhan berpusat pada PC. Langkah-langkah atau alur jalannya kontrol yang dilakukan PC sepenuhnya diatur oleh program utama yang 
dalam hal ini menggunakan bahasa pemrograman Delphi 7.

Pada Sistem ini program terlebih dahulu mendeteksi keadaan sensor dan tombol pada masing-masing ruangan. Pemrosesan data sensor dan tombol pada ruangan diurutkan mulai dari ruangan 1 sampai ruangan 24. Data sensor dan tombol yang ditampilkan merupakan kondisi low (0). Tombol pada tampilan program akan menunjukkan warna kuning jika semua kondisi high (1).

Pengujian dari keseluruhan alat yang telah dilakukan, program akan mengecek kondisi sensor dan tombol pada masing-masing ruangan, apabila salah satu tombol pada tampilan program atau tombol pada ruangan diklik/ditekan, maka program akan mengirimkan perintah logika 1 pada shift register yang diteruskan ke driver relay yang berfungsi menggerakkan relay sehingga output lampu akan menyala. Cahaya lampu di masing-masing ruangan akan ditangkap sensor fotodioda yang berfungsi merubah besaran cahaya menjadi besaran listrik. Selanjutnya perintah akan diteruskan ke program sehingga tombol lampu pada tampilan program akan berwarna kuning (tanda lampu nyala). Jika salah satu lampu tidak terpasang atau putus maka tombol lampu pada tampilan program akan berwarna merah

Hasil pengujian sistem kontrol lampu pada gedung bertingkat berbasis PC dapat dilihat pada tabel 4.3 dan tabel 4.4. Diasumsikan bahwa sebelum data diambil kondisi sistem dalam keadaan low (0) atau tidak ada masukan (belum ada lampu yang menyala). Dari tabel tersebut dapat dilihat bahwa ketika salah satu tombol pada tampilan program atau tombol pada ruangan ditekan maka output lampu akan menyala dan jika ditekan lagi maka output lampu akan padam. Hal ini menunjukkan bahwa sistem mampu bekerja sesuai dengan perencanaan

\section{KESIMPULAN}

1. Kontrol lampu pada gedung bertingkat berbasis PC ini terdiri dari 2 rancangan utama, yaitu rancangan mekanik (miniatur ruangan, lampu, tombol, relay dan sensor fotodioda) dan rancangan elektronik (LM311, shift register input, shift register output, ULN 2003 dan DB 25). Prinsip kerja alat adalah ketika salah satu tombol pada tampilan program atau pada ruangan diklik/ditekan maka program mengirimkan perintah berupa logika "1" mela lui shift register, kemudian dikuatkan oleh driver relay (ULN2003) sehingga mampu menggerakkan relay yang menyebabkan lampu menyala. Cahaya lampu akan ditangkap oleh sensor fotodioda dan diubah menjadi besaran listrik yang akan diproses oleh PC. Tombol pada tampilan program akan berwarna kuning ketika lampu menyala dan berwarna merah ketika lampu putus atau tidak terpasang.

2. Perangkat lunak dari sistem yang dibuat (Delphi 7) dapat mengatur dan menentukan langkah-langkah yang harus dilakukan shift register pada keseluruhan sistem yang dibuat.

\section{DAFTAR PUSTAKA}

Abdullah, Robith. 2003. Perencanaan dan Pembuatan Miniatur Sistem Parkir Berbasis Personal Computer Menggunakan PPI Card 825 5.Malang: Politeknik Negeri Malang

Anonymous. 2002. Intefacing The Standard Parallel Port. http://www.senet.com.au/ peacock Tanggal 25 Desember 2008 jam 10.00 WIB

Budiharto, Widodo dan Sigit Firmansah. 2005. Elektronika Digital dan Mikroprosesor. Yogyakarta: ANDI

Djamin, Martin. 2008. Penghematan Energi dan Kebebasan Konsumen. Artikel Iptek. 
http://www.ristek.go.id Tanggal 19 Februari 2009 jam 10.50 WIB

Iswanto. 2008. Antarmuka Port Paralel dan Port Serial dengan Delph $i$ 6.Yogyakarta: Gava Media

Juwitasari, Diana Fitri. 2005. Perencanaan dan Pembuatan Stasiun Mini Pemantauan Cuaca Dengan Menggunakan PC. Malang: POLITEKNIK NEGERI MALANG

Malvino, Albert Paul. 1985. Prinsip-Prinsip Elektronika . Jakarta: Erlangga.

Malvino, Albert Paul. 2003. Prinsip-Prinsip Elektronika . Jakarta: Salemba Teknika.

Petruzella, Frank D. 2001. Elektronika Industri. Yogyakarta: Andi.

Putranto, Agus Dkk. 2008. Teknik Otomasi Industri.Jakarta: Direktorat Jenderal Manajemen Pendidikan Dasar dan Menengah, Direktorat Pembinaan Sekolah Menengah Kejuruan, Departemen Pendidikan Nasional

Safitri, Ahmad. 2006. Aplikasi MCS-51 Secara Master-Slave Sebagai Sistem Pengontrol Lampu dan Penerangan dan Pengamanan Pada Gedung Bertingkat. Malang: Fakultas Teknik Universitas Brawijaya

Soedarto, Gatot.2000. Dasar-Dasar Sistem Digital. Surabaya: Usaha Nasional

Suprayogi, Bangun. 2006.Perancangan dan Pembuatan Simulasi Pengisian dan Pengosongan Otomatis Tanur Dapur Listrik. Malang: Politeknik Negeri Malang

Tokheim, Roger L. 1990. Elektronika Digital Edisi Kedua.Jakarta: Erlangga

Tokheim, Roger L. 1996. Prinsip-prinsip Digital Edisi Kedua. Jakarta: Erlangga

Widjanarka, Ir Wijaya. 2006.Teknik Digital.Jakarta: Erlangga

Widodo, Budhi Romy. 2007. Interfacing Paralel dan Serial menggunakan Delphi.Yogyakarta: Graha Ilmu

www.teknisoft.netprojectskpl.php Tanggal 25 Desember 2008 jam 10.00 WIB

www.iptek.net.id Tanggal 19 Februari 2009 jam 11.09 WIB

www.ilkom.unsri.ac.id Tanggal 5 Juli 2009 jam 09.15

http://blogspot.com Tanggal 5 Juli 2009 jam 09.15 